\title{
The Customer Is Always Right: Determinants and Outcomes of Consumer Value Co-Destruction: An Abstract
}

\author{
Joanne T. Cao and Bruce L. Alford
}

\begin{abstract}
Common wisdom acknowledges that the customer is not always right. Consumers may seem disinclined to follow organizational rules and norms that prescribe compliance during a service encounter (e.g., Fisk et al., 2010). This notion of consumer misbehavior is evident in the value co-creation literature in which certain behaviors, such as consumer participation, may result in undesired consequences. However, only a few studies have fully examined the opposite possibility of value co-creation and value co-destruction (VCD). There has been scant research on VCD, especially within the realm of professional services, and few have only hinted at the notion of co-creating efforts leading to negative value. Therefore, this research puts forth a conceptual model of the VCD process, in which resource disintegration is a key component to value not being realized in the dyad. Specifically, this paper focuses on the consumers' role in VCD and offers propositions in which factors or characteristics encourage consumers to behave badly in a service encounter. Contributions and future research are discussed.
\end{abstract}

References Available Upon Request

\footnotetext{
J.T. Cao $(\bowtie)$

University of Southern Mississippi, Hattiesburg, MS, USA

e-mail: joanne.cao@usm.edu
}

B.L. Alford

Louisiana Tech University, Ruston, LA, USA

e-mail: balford@latech.edu 